\title{
KONDISI SOSIAL EKONOMI NELAYAN DI DESA BULAWAN II, KECAMATAN KOTABUNAN, KABUPATEN BOLAANG MONGONDOW TIMUR
}

\author{
Djirhan Mokoagow'; Srie J. Sondakh'; Martha P. Wasak ${ }^{2}$ \\ 1)Mahasiswa Fakultas Perikanan dan IImu Kelautan Universitas Sam Ratulangi Manado \\ 2)Staff Pengajar Fakultas Perikanan dan IImu Kelautan Universitas Sam Ratulangi Manado \\ Koresponden email : jirhanmokoagow966@gmail.com
}

\begin{abstract}
The purpose of this study was to determine the social and economic conditions of fishermen in Bulawan II Village, Kotabunan Subdistrict, and East Bolaang Mongondow District. This type of research is descriptive, where descriptive research is a study that aims to express a social reality by describing precisely the characteristics of individuals, circumstances, symptoms, certain groups relating to the problem of units studied in society. The population in this study was fishing fishermen in Bulawan II Village, Kotabunan District, East Bolaang Mongondow Regency. Based on preliminary observations the number of fishing populations in Bulawan II Village is 23 people. Samples taken were $20 \%$ or as many as 20 people using simple random sampling. The existence of fishermen in Bulawan II Village has not been widely reported to date either in the form of scientific writings or researches, readings in the form of articles and so on, so there needs to be research that reveals the state of the socio-economic conditions of fisherman.
\end{abstract}

Key Words: Bulawan II, fishermen, social conditions, economic conditions

\begin{abstract}
Abstrak
Tujuan dari penelitian ini adalah untuk mengetahui kondisi sosial dan ekonomi nelayan di Desa Bulawan II Kecamatan Kotabunan Kabupaten Bolaang Mongondow Timur. Jenis penelitian ini adalah deskriptif, dimana penelitian bersifat deskriptif merupakan penelitian yang bertujuan untuk mengungkapkan suatu kenyataan sosial dengan jalan mendeskripsikan secara tepat sifat-sifat individu, keadaan, gejala, kelompok tertentu berkenaan dengan masalah unit yang diteliti dalam masyarakat. Populasi dalam penelitian ini adalah nelayan penangkap ikan di Desa Bulawan II, Kecamatan Kotabunan Kabupaten Bolaang Mongondow Timur. Berdasarkan pengamatan awal jumlah populasi nelayan yang ada di Desa Bulawan II sebanyak 23 orang. Sampel yang diambil sebesar $20 \%$ atau sebanyak 20 orang dengan menggunakan metode pengambilan secara acak sederhana atau simple random sampling. Keberadaan nelayan di Desa Bulawan II sampai saat ini belum banyak diberitakan baik berupa tulisantulisan ilmiah maupun penelitian-penelitian, bacaan-bacaan berbentuk artikel dan lain sebagainya, sehingga perlu adanya penelitian yang mengungkapkan tentang keadaan kondisi sosial ekonomi nelayan.
\end{abstract}

Kata Kunci: Bulawan II, nelayan, kondisi sosial, kondisi ekonomi

\section{PENDAHULUAN}

Sumber Daya Manusia (SDM) atau human recources mengandung dua pengertian. Pertama, adalah usaha kerja atau jasa yang dapat diberikan dalam proses produksi atau SDM kualitas usaha yang diberikan oleh seseorang dalam waktu tertentu untuk menghasilkan barang dan jasa. Pengertian kedua, SDM menyangkut seseorang yang mampu bekerja untuk memberikan jasa atau usaha kerja tersebut. Mampu bekerja berarti mampu melakukan kegiatan yang mempunyai nilai ekonomis, yaitu bahwa kegiatan tersebut menghasilkan barang atau jasa untuk memenuhi kebutuhan hidup seseorang atau masyarakat (Sumarsono, 2003). Sehubungan dengan hal ini sumber daya manusia dalam kegiatan perikanan sangat penting dan salah satu yang memegang peranan penting adalah masyarakat pesisir khususnya nelayan. Pembangunan sektor perikanan merupakan bagian intergral yang diarahkan untuk meningkatkan pendapatan dan taraf hidup nelayan, Pembangunan perikanan meliputi dua aspek yaitu aspek fisik antara lain 
menyangkut pembangunan sarana dan prasarana perikanan dalam rangka meningkatkan kualitas dan kuantitas produksi, serta aspek manusia yang tentunya diperuntukkan bagi peningkatan taraf hidup demi kesejahteraan keluarga nelayan secara adil dan merata dengan memanfaatkan sumberdaya alam pesisir secara bertanggung jawab dan berkesinambungan (Dahuri dkk., 2008).

Masyarakat nelayan merupakan salah satu bagian masyarakat yang hidup dengan mengelola potensi sumber daya perikanan, di mana masyarakatnya tinggal di kawasan pesisir, mempunyai karakteristik sosial tersendiri yang berbeda dengan masyarakat yang lain. Di beberapa kawasan pesisir yang relatif berkembang pesat, struktur masyarakatnya bersifat heterogen, memiliki etos kerja yang tinggi, solidaritas yang kuat, serta terbuka terhadap perubahan dan interaksi sosial. Sekalipun demikian, masalah kemiskinan masih melanda sebagian masyarakat pesisir, ditandai oleh adanya beberapa ciri, seperti kemiskinan, keterbelakangan sosial-budaya, rendahnya sumber daya manusia, sehingga pada saat ini dapat dilihat bahwa sebagian besar masyarakat pesisir masih berada dibawah garis kemiskinan (Nasution, 2005).

\section{METODE PENELITIAN}

Jenis penelitian ini adalah deskriptif, dimana penelitian bersifat deskriptif merupakan penelitian yang bertujuan untuk mengungkapkan suatu kenyataan sosial dengan jalan mendeskripsikan secara tepat sifat-sifat individu, keadaan, gejala, kelompok tertentu berkenaan dengan masalah unit yang diteliti dalam masyarakat (Faisal, 2003).

Metode penelitian pada dasarnya merupakan cara ilmiah untuk mendapatkan data dengan tujuan dan kegunaan tertentu. Untuk mencapai tujuan tersebut diperlukan suatu metode yang relevan dengan tujuan yang ingin dicapai. Metode penelitian yang digunakan penulis adalah metode survei. Menurut Sugiyono (2013), pengertian metode survey adalah penelitian yang dilakukan dengan menggunakan angka sebagai alat penelitian yang dilakukan pada populasi besar maupun kecil, tetapi data yang dipelajari adalah data dari sampel yang diambil dari populasi tersebut, sehingga ditemukan kejadian relatif, distribusi dan hubungan antar variabel, sosiologis maupun psikologis.

Populasi dalam penelitian ini adalah nelayan penangkap ikan di Desa Bulawan II, Kecamatan Kotabunan Kabupaten Bolaang Mongondow Timur. Berdasarkan pengamatan awal jumlah populasi nelayan yang ada di Desa Bulawan II sebanyak 23 orang. Sampel yang diambil sebesar $20 \%$ atau sebanyak 20 orang dengan menggunakan metode pengambilan secara acak sederhana atau simple random sampling.

\section{HASIL DAN PEMBAHASAN}

Keadaan Penduduk Desa Bulawan II

Etnik penduduk yang terdapat di Desa Bulawan II terdiri dari Suku Mongondow, Suku Gorontalo, Suku Sangihe, dan Suku Minahasa, dapat dilihat pada Tabel 1 di bawah ini. 
Tabel 1. Jumlah Penduduk Desa Bulawan II Berdasarkan Suku

\begin{tabular}{|c|c|c|c|}
\hline No & Suku & Jumlah & $\begin{array}{c}\text { Persentase } \\
(\%)\end{array}$ \\
\hline 1 & Mongondow & 402 & 33 \\
\hline 2 & Gorontalo & 608 & 50 \\
\hline 3 & Sanggihe & 108 & 9 \\
\hline 4 & Minahasa & 98 & 8 \\
\hline & Total & 1,216 & 100 \\
\hline
\end{tabular}

Sumber: Data sekunder diolah, 2019.

Tabel 1 menunjukkan bahwa etnik yang paling banyak mendiami Desa Bulawan II adalah suku Mongondow dengan jumlah 402 jiwa atau 33\% selanjutnya Gorontalo sebanyak $50 \%$, Sangihe 9\%, dan Minahasa 8\%.

Penduduk yang ada di Desa Bulawan II berjumlah 1.216 jiwa, terdiri dari masing-masing jaga yaitu: Dusun I 302 jiwa, $\quad$ Dusun II 408 jiwa, Dusun III 208 jiwa, Dusun IV 298 jiwa.

Penduduk Desa Bulawan ॥ memiliki mata pencaharian penduduk seperti terlihat pada Tabel 2 di bawah ini,

Tabel 2. Jenis Mata Pencaharian Pokok

Penduduk Desa Bulawan II

\begin{tabular}{|c|l|c|c|}
\hline No & Jenis Pekerjaan & Jumlah & $(\%)$ \\
\hline 1 & Petani & 131 & 54 \\
\hline 2 & Nelayan & 23 & 5 \\
\hline 3 & Sopir \& Tukang Ojek & 34 & 7 \\
\hline 4 & PNS & 11 & 2 \\
\hline 5 & Wiraswasta/Pedagang & 16 & 3 \\
\hline 6 & Lain-lain & 255 & 54 \\
\hline \multicolumn{2}{|r|}{ Total } & 470 & 100 \\
\hline
\end{tabular}

Sumber: Data sekunder diolah, 2019

Tabel 2 menunjukkan bahwa mata pencaharian penduduk Desa Bulawan II yang dominan adalah petani dan nelayan berjumlah 154 jiwa. Hal ini disebabkan karena kakek-nenek yang dahulu banyak yang tidak tamat sekolah sehingga tidak memiliki ijazah untuk melamar pekerjaan. Berdasarkan wawancara langsung pada saat penelitian diketahui bahwa mereka hanya memanfaatkan keahlian yang mereka dapatkan dari pengalaman sehingga mereka hanya bisa bekerja misalnya menjadi sopir dan tukang ojek. Pekerjaan yang mereka jalani demi untuk memenuhi kebutuhan sehari-hari. Selanjutnya yang bekerja wiraswasta/dagang berjumlah 16 jiwa atau $3 \%$. dan sisanya PNS $2 \%$ dan sopir/ojek $7 \%$.

Nelayan di Desa Bulawan II paling banyak bermukiman di Dusun I, dimana wilayahnya berada pada tepat di pesisir pantai. Berikut ini jumlah nelayan menurut Dusun di Desa Bulawan II.

Tabel 3. Jumlah Penduduk Bulawan II Menurut Dusun

\begin{tabular}{|c|l|c|c|}
\hline No & \multicolumn{1}{|c|}{ Suku } & Jumlah & $\begin{array}{c}\text { Persentase } \\
(\%)\end{array}$ \\
\hline 1 & Dusun I & 302 & 25 \\
\hline 2 & Dusun II & 408 & 34 \\
\hline 3 & Dusun III & 208 & 17 \\
\hline 4 & Dusun IV & 298 & 25 \\
\hline \multicolumn{2}{|c|}{ Total } & 1,216 & 100 \\
\hline
\end{tabular}

Sumber: Data primer, 2019.

Tabel 3 menunjukkan penduduk yang berada di dusun I, berjumlah 302 orang atau $25 \%$, dusun II berjumlah 408 orang atau $34 \%$, dan yang terakhir jumlah penduduk yang bertempat tinggal di dusun III adalah 208 orang atau 17\% dan dusun IV sebanyak 298 orang atau $25 \%$. Jumlah nelayan dusun I yang terbanyak dan mendominasi Bulawan II. Mereka memilih tinggal di wilayah tersebut karena wilayah tersebut paling dekat dengan pantai, sehingga lebih memudahkan akses ke laut.

Gambaran mengenai umur nelayan responden di Desa Bulawan II dapat dilihat pada Tabel 4.

Tabel 4. Jumlah Responden Menurut Umur di Desa Bulawan II

\begin{tabular}{|c|c|c|c|}
\hline No & $\begin{array}{c}\text { Kelompok Umur } \\
\text { (Tahun) }\end{array}$ & Jumlah & $\begin{array}{c}\text { Persentase } \\
(\%)\end{array}$ \\
\hline 1 & $30-39$ & 5 & 25 \\
\hline 2 & $40-49$ & 13 & 65 \\
\hline 3 & $50-65$ & 2 & 10 \\
\hline \multicolumn{2}{|r|}{ Total } & 20 & 100 \\
\hline
\end{tabular}

Sumber: Data primer, 2019. 
Tabel 4 menunjukkan umur nelayan responden di lokasi penelitian dimana $25 \%$ atau 5 responden berumur 30-39 tahun sedangkan sisanya 13 responden atau $65 \%$ berumur $40-49$ tahun, dan $10 \%$ atau 2 responden berumur 50-65. Umur seseorang menentukan prestasi kerja atau kinerja orang tersebut. Semakin berat pekerjaan secara fisik maka memerlukan tenaga yang semakin kuat, tenaga kerja akan semakin turun prestasinya jika umurnya sudah lebih dari 64 tahun. Namun, dalam hal tanggung jawab semakin tua umur seseorang akan semakin bijak dan bertanggung jawab karena semakin berpengalaman. Tarigan (2009) seorang nelayan yang berumur di atas 30 tahun dianggap sebagai nelayan berpengalaman, serta mampu menerima inovasi dari luar. Nelayan di lokasi penelitian dimana rata-rata nelayan memiliki pengalaman walaupun usia masih pada kisaran 30 tahun sampai 49 tahun. Sebagai nelayan tentunya dengan pengalaman kerja yang ada, mereka dengan mudah menemukan daerah penangkapan ikan walaupun hanya seputaran wilayah pesisir Desa Bulawan II.

Umur juga mempengaruhi produktivitas kerja nalayan di daerah penelitian dimana rata-rata nelayan yang mampu bekerja menangkap ikan dilaut selama kurang lebih 12 jam dalam sehari atau dimulai dari jam 5 sore sampai jam 5 pagi. Payman Simanjuntak (1985) mengemukakan produktivitas kerja seseorang dapat meningkat seiring dengan pertambahan usia. Rata-rata nelayan di daerah penelitian masih tergolong berusia produktif bisa bekerja secara optimal mengingat kondisi fisik mereka cukup baik serta tenaga yang masih sangat kuat dalam bekerja. Tingkat pendidikan nelayan responden di
Desa Bulawan II dapat dilihat pada Tabel 5.

Tabel 5. Jumlah Responden Menurut Tingkat Pendidikan di Desa Bulawan II

\begin{tabular}{|c|c|c|c|}
\hline No & Tingkat Pendidikan & Jumlah & $\begin{array}{c}\text { Persentase } \\
(\%)\end{array}$ \\
\hline 1 & SD & 12 & 60 \\
\hline 2 & SMP & 5 & 25 \\
\hline 3 & SMA & 3 & 15 \\
\hline \multicolumn{2}{|c|}{ Total } & 20 & 100 \\
\hline
\end{tabular}

Sumber: Data primer, 2019.

Tabel 5 menunjukkan bahwa kebanyakan nelayan responden memiliki pendidikan terakhir sekolah dasar (SD) berjumlah 12 orang atau $60 \%$. Hal itu disebabkan karena dari Yatar belakang orang tua pada waktu yang lalu belum memahami arti pendidikan yang sebenarnya, sehingga selain tidak mampu untuk membiayai pendidikan karena penghasilan minim serta jumlah tanggungan keluarga yang banyak sebagai nelayan. Hal lainnya juga karena tempat tinggal di tepi pantai atau pesisir sehingga lebih cepat bekerja sebagai nelayan dari pada mengenyam pendidikan di bangku sekolah. Sedangkan Sekolah Menengah Pertama (SMP) berjumlah 5 orang atau $25 \%$, dan sisanya adalah tamatan Sekolah Menengah Atas (SMA) berjumlah 3 atau $15 \%$. Berdasarkan data tersebut dapat disimpulkan bahwa pendidikan nelayan responden di Desa Bulawan II masih sangat rendah. Hasil wawancara dengan responden, terbatasnya biaya yang dimiliki oleh orang tua mereka pada saat itu sehingga para anak nelayan yang dahulu waktu masih berada pada usia sekolah memilih berhenti dan memutuskan untuk bekerja atau berprofesi sebagai nelayan. Bekerja sebagai nelayan dapat membantu untuk mencukupi kebutuhan rumah tangga orang tua mereka. Penyebab lain yaitu karena kurangnya kesadaran dari para 
nelayan tentang pentingnya pendidikan. Para nelayan pada saat itu belum mampu berpikir bahwa dengan melanjutkan sekolah bisa ada jaminan masa depan yang lebih menjanjikan.

Kesehatan merupakan salah satu aspek yang paling penting bagi nelayan. Berdasarkan hasil wawancara dengan responden diketahui bahwa kesehatan nelayan responden terbilang baik, karena jarang mengalami sakit yang serius. Agar lebih jelasnya kondisi kesehatan nelayan responden dapat dilihat pada Tabel 6 berikutnya ini.

Tabel 6. Jumlah Responden Menurut Kesehatan di Desa Bulawan II

\begin{tabular}{|c|l|c|c|}
\hline No & Kondisi Kesehatan & Jumlah & $(\%)$ \\
\hline 1 & Tidak Pernah Sakit & 8 & 40 \\
\hline 2 & Jarang Sakit & 10 & 50 \\
\hline 3 & Sering Sakit & 2 & 10 \\
\hline \multicolumn{2}{|c|}{ Total } & 20 & 100 \\
\hline
\end{tabular}

Sumber: Data primer, 2019.

Tabel 6 menunjukkan kondisi kesehatan nelayan di Desa Bulawan II. Berdasarkan wawancara dengan responden, diketahui nelayan hanya mengalami gangguan kesehatan yang ringan seperti flu, demam @dan nyeri sendi. Kondisi seperti ini sering atau biasa dialami oleh nelayan. Selanjutnya nelayan yang jarang sakit berjumlah 10 orang atau $50 \%$, dan yang sering sakit berjumlah 2 orang atau $10 \%$. Hal ini disebabkan karena faktor umur, mengingat nélayan responden ada yang telah berumur 65 tahun. Kondisi rumah nelayan di Desa Bulawan II dapat dilihat pada Tabel 7 berikut ini.

Tabel 7. Jumlah Responden Menurut Kondisi Rumah di Desa Bulawan II

\begin{tabular}{|c|l|c|c|}
\hline No & \multicolumn{1}{|c|}{ Kondisi Rumah } & Jumlah & $\begin{array}{c}\text { Persentase } \\
(\%)\end{array}$ \\
\hline 1 & Permanen & 6 & 30 \\
\hline 2 & Semi permanen & 7 & 35 \\
\hline 3 & Papan & 3 & 15 \\
\hline 4 & Tripleks & 4 & 20 \\
\hline \multicolumn{2}{|c|}{ Total } & 20 & 100 \\
\hline
\end{tabular}

Sumber: Data primer, 2019.
Tabel 7 menunjukkan kondisi rumah nelayan di Desa Bulawan II. Berdasarkan wawancara dengan responden yang paling banyak mempunyai rumah semi permanen ada 7 orang atau $35 \%$ dan yang paling sedikit adalah rumah papan dan tripleks yaitu 7 orang atau $35 \%$. Hasil penelitian menggambarkan bahwa untuk aspek perumahan nelayan responden di Desa Bulawan II dapat dikatakan sudah baik karena $65 \%$ rumah nelayan responden sudah semi permanen bahkan ada yang permanen.

Kondisi perumahan yang baik ini disebabkan karena adanya bantuan pemerintah berupa bedah rumah walaupun tidak seluruhnya mendapatkan bantuan ini, karena ada syarat bagi penerima bantuan rumah bedah antara lain harus memiliki lahan sendiri. Sehingga terdapat beberapa rumah baik permanen maupun rumah semi permanen yang dimiliki oleh nelayan merupakan bantuan dari pemerintah kabupaten maupun propinsi Sulawesi Utara. Masih ada beberapa rumah sangat sederhana (seperti rumah papan atau tripleks) yang dimiliki nelayan responden terutama yang tinggal di daerah pesisir pantai atau tepatnya yang berada di dusun I dan II karena dari hasil wawancara bahwa lahan tempat tinggal nelayan merupakan milik pemerintah.

Masyarakat Desa Bulawan II juga memeluk agama yaitu Kristen, Katolik dan Islam, dapat dilihat pada Tabel 8.

Tabel 8. Jumlah Responden Menurut Agama di Desa Bulawan II

\begin{tabular}{|c|l|c|c|}
\hline No & \multicolumn{1}{|c|}{ Agama } & $\begin{array}{c}\text { Jumlah } \\
\text { (jiwa) }\end{array}$ & $\begin{array}{c}\text { Persentase } \\
\text { (\%) }\end{array}$ \\
\hline 1. & Kristen & 5 & 25 \\
\hline 2. & Katolik & 3 & 15 \\
\hline 3. & Islam & 12 & 60 \\
\hline \multicolumn{2}{r|}{ Total } & 20 & 100 \\
\hline
\end{tabular}

Sumber: Data Sekunder, 2019.

Tabel 8 dapat dilihat bahwa sebagian besar Desa Bulawan II yang 
memeluk agama Kristen yaitu sebanyak 5 orang $(25 \%)$, Katolik sebanyak 3 orang $(15 \%)$, dan Islam sebanyak 12 orang $(60 \%)$. Kehidupan beragama di Desa Bulawan II terjalin baik, karena sudah lama tinggal di lingkungan yang sama saling berdampingan satu sama lain.

Tempat ibadah di Desa Bulawan II yaitu untuk agama Islam sebuah Mesjid Multazam yang berada di Desa Bulawan Induk, sedangkan Kristen dan Katolik tidak ada tempat ibadah, dan biasanya beribadah di Gereja GMIBM dan Katolik di Desa Kotabunan Selatan dan Gereja Pantekosta Desa Kotabunan Induk. Tabel 9 memperlihatkan jumlah tanggungan keluarga nelayan di Desa Bulawan II.

Tabel 9. Jumlah Responden Menurut Tanggungan Keluarga di Desa Bulawan II

\begin{tabular}{|c|c|c|c|}
\hline No & $\begin{array}{c}\text { Tanggungan } \\
\text { Keluarga }\end{array}$ & Jumlah & $\begin{array}{c}\text { Persentase } \\
(\%)\end{array}$ \\
\hline 1 & 4 & 3 & 15 \\
\hline 2 & $5-6$ & 11 & 55 \\
\hline 3 & $>7$ & 6 & 30 \\
\hline \multicolumn{2}{|c|}{ Total } & 20 & 100 \\
\hline
\end{tabular}

Sumber: Data primer, 2019

Tabel 9 menunjukkan bahwa jumlah tanggungan keluarga yang paling sedikit 4 orang itu seperti mama, papa dan 2 orang anaknya berjumlah 4 responden atau $15 \%$, hal ini karena mereka mengikuti program pemerintah yaitu Keluarga Berencana (KB), berdasarkan wawancara dengan nelayan pada waktu itu diketahui para nelayan beralasan bahwa dengan jumlah tanggungan yang sedikit akan lebih mudah untuk memenuhi kebutuhan sehari-hari. Jumlah tanggungan keluarga nelayan juga merupakan faktor pendorong nelayan untuk giat bekerja mencari nafkah agar dapat memenuhi semua kebutuhan keluarga. Hal ini dapat dibuktikan, setiap kali datang ke lokasi ternyata hampir semua nelayan rajin turun melaut menangkap ikan. Pada saat tidak turun melaut mereka melakukan pekerjaan sampingan sebagai penambang atau tukang ojek motor. Tabel 10 adalah klasifikasi jumlah modal nelayan di Desa Bulawan II.

Tabel 10. Jumlah Responden Menurut Modal Operasional per Bulan di Desa Bulawan II

\begin{tabular}{|c|l|c|c|}
\hline No & \multicolumn{1}{|c|}{ Modal Usaha } & Jumlah & $\begin{array}{c}\text { Persentase } \\
(\%)\end{array}$ \\
\hline 1 & $<\operatorname{Rp~500.000,-}$ & 6 & 30 \\
\hline 2 & $\begin{array}{l}\text { Rp 500.000,- - Rp } \\
2.000 .000,-\end{array}$ & 6 & 30 \\
\hline 3 & $>\operatorname{Rp~2.000.000,-}$ & 8 & 40 \\
\hline \multicolumn{2}{|c|}{ Total } & 20 & 100 \\
\hline
\end{tabular}

Sumber: Data primer, 2019.

Tabel 10 menunjukkan bahwa modal yang dikeluarkan untuk keperluan penangkapan dalam hal ini nelayan pancing terdapat 6 reponden atau $30 \%$ yang menggunakan modal kurang dari Rp 500.000,-. Berdasarkan wawancara diketahui bahwa modal operasional yang dikeluarkan sedikit karena alat tangkap yang dipergunakan sangat sederhana seperti pancing noru, pancing dasar.

Sedangkan modal yang dikeluarkan antara $R p 500.000,-$ - Rp 2.000.000,- berjumlah 6 responden atau $30 \%$. Berdasarkan wawancara dengan responden, nelayan tersebut mengeluarkan modal biaya produksi bagan sebesar $\mathrm{Rp}$ 500.000,- - Rp 2.000.000,- untuk membeli bahan bakar, makanan/minuman, dan keperluan lainnya ketika mnelakukan penangkapan. Sedangkan modal yang dikeluarkan nelayan lebih dari $\mathrm{Rp}$ 2.000.000,- berjumlah 8 orang atau 40\%. Bahwa modal operasional yang dikeluarkan begitu besar karena menggunakan alat bantu penangkapan berupa perahu lampu untuk keperluan penerangan ketika melakukan penangkapan dengan soma pajeko. 
Tabel 11. Jumlah Responden Menurut Pendapatan di Desa Bulawan II

\begin{tabular}{|c|c|c|c|}
\hline No. & $\begin{array}{c}\text { Pendapatan Pokok } \\
(\mathbf{R p})\end{array}$ & $\begin{array}{c}\text { Jumah } \\
\text { Nelayan }\end{array}$ & $\begin{array}{c}\text { Persentase } \\
(\mathbf{\%})\end{array}$ \\
\hline 1 & $<1.000 .000,0$ & 10 & 50 \\
\hline 2 & $\begin{array}{c}1.000 .000 \\
2.000 .000\end{array}$ & 8 & 40 \\
\hline 3 & $>2.000 .000,-$ & 2 & 10 \\
\hline & Total & 20 & 100 \\
\hline
\end{tabular}

Sumber: data primer diolah, 2019.

Tabel 11 menunjukan bahwa pendapatan nelayan Desa Bulawan II yang paling banyak adalah yang mempunyai pendapatan kurang dari $\mathrm{Rp}$ 1.000 .000 ,-yaitu 10 orang atau $50 \%$. Hal ini dikarenakan mereka hanya memiliki alat tangkap yang sederhana seperti pancing Noru atau Soma Dampar, yang daerah penangkapannyapun tidak jauh dari pantai. Peralatan yang sederhana tidak memungkinkan mereka mencari daerah penangkapan yang jauh karena akan penuh resiko. Daerah penangkapan yang tidak jauh dari pantai tentu hasil yang diperolehpun sangat terbatas, inilah penyebabnya mereka mempunyai pendapatan yang kurang dari Rp 1.000.000,--

Bagi nelayan yang mempunyai alat tangkap yang lebih modern dengan mesin motor yang lebih besar akan dapat mencari daerah penangkapan yang lebih jauh dan dapat mencari gerombolan ikan sebagai sasaran tangkapan mereka. Berdasarkan alat tangkap yang mereka punya mereka dapat menentukan jenis ikan apa yang ingin mereka tangkap, sehingga mereka lebih selektif dalam menangkap ikan. Inilah penyebabnya mereka mempunyai pendapatan yang lebih tinggi yaitu antara Rp 1.000.000,- - Rp 2.000.000,bahkan ada yang lebih besar dari $\mathrm{Rp}$ 2.000.000,-. Nelayan yang mempunyai pendapatan lebih besar dari $\mathrm{Rp}$ 2.000 .000 ,- sebanyak 2 orang atau 10\% sedangkan yang mempunyai pendapatan antara $R p$ 1.000.000,- - Rp 2.000.000,- sebanyak 8 orang atau $40 \%$.

Selain banyaknya hasil tangkapan yang mempengaruhi pendapatan nelayan, juga frekuensi atau sering tidaknya mereka ke laut mencari ikan. Bagi nelayan yang masih mempunyai peralatan yang sangat sederhana sangat terkendala dengan cuaca atau musim, karena kalau cuaca tidak bersahabat maka mereka tidak berani ke laut. Pada saat angin kencang dan ombak besar nelayan tidak dapat mencari ikan sehingga tidak mendapat penghasilan dari profesi nelayan, namun mereka juga tidak duduk manis di rumah, tetapi mencari pekerjaan lain seperti menjadi petani atau tukang atau bahkan menjadi penambang. Hal inilah yang akan menambah penghasilan selain dari menangkap ikan. Rata-rata nelayan di Desa Bulawan II semua mempunyai pekerjaan sampingan untuk mengantisipasi apabila cuaca buruk dan mereka tidak bisa ke laut, agar mereka tetap mempunyai penghasilan untuk membiayai kehidupan keluarga mereka.

Tabel 12. Jumlah Responden Berdasarkan Pekerjaan Sambilan

\begin{tabular}{|c|l|c|c|}
\hline No & \multicolumn{1}{|c|}{$\begin{array}{c}\text { Pekerjaan } \\
\text { Sambilan }\end{array}$} & Jumlah & $\begin{array}{c}\text { Persentase } \\
(\%)\end{array}$ \\
\hline 1 & Tukang bangunan & 10 & 50 \\
\hline 2 & Petani & 8 & 40 \\
\hline 4 & Penambang & 2 & 10 \\
\hline \multicolumn{2}{|c|}{ Jumlah } & 20 & 100 \\
\hline
\end{tabular}

Sumber: Data primer diolah, 2019.

Berdasarkan hasil penelitian didapatkan yang paling banyak melakukan pekerjaan sampingan adalah tukang bangunan sebanyak 10 orang atau 50\%. Karena banyak pembangunan yang dilakukan di desa tersebut seperti perumahan, warung-warung, sedangkan petani 8 orang atau $40 \%$, dan pekerjaan sampingan penambang ada 2 orang atau $10 \%$ pekerjaan ini adalah untuk memenuhi kebutuhan sehari-hari mereka. 
Pekerjaan sebagai nelayan memang menjadi pekerjaan mayoritas masyarakat di Desa Bulawan II, akan tetapi sebagian besar nelayan berpendapat, bahwa pendapatan dari pekerjaan sebagai nelayan saja ternyata belum mampu mencukupi kebutuhan hidup keluarganya, sehingga sebagian besar nelayan dalam penelitian ini memiliki pekerjaan sampingan, ketika sedang tidak melaut, atau pada musim panceklik.

Tabel 13. Jumlah Responden Menurut Pengeluaran di Desa Bulawan II

\begin{tabular}{|c|c|c|c|}
\hline No & $\begin{array}{c}\text { Pengeluaran } \\
(\mathbf{R p})\end{array}$ & $\begin{array}{c}\text { Jumah } \\
\text { Nelayan }\end{array}$ & $\begin{array}{c}\text { Persentase } \\
(\mathbf{\%})\end{array}$ \\
\hline 1 & $<1.000 .000,-$ & 11 & 55 \\
\hline 2 & $\begin{array}{c}1.000 .000,- \\
2.000 .000,-\end{array}$ & 8 & 40 \\
\hline 3 & $>2.000 .000,-$ & 1 & 5 \\
\hline & Total & 20 & 100 \\
\hline
\end{tabular}

Sumber: Data primer diolah, 2019.

Berdasarkan Tabel 13 dapat disimpulkan bahwa pengeluaran rumah tangga nelayan kebanyakan masih di bawah Rp 1.000.000,- per bulan yaitu 11 orang atau $55 \%$. Hal ini dimaklumi karena selain penghasilan mereka yang kecil juga mereka hidup jauh dari ibu kota propinsi sehingga penghidupannya masih didominasi oleh alam pedesaan. Rata-rata masyarakat nelayan memiliki lahan pertanian yang digarap untuk memenuhi kebutuhan hidup setiap hari, sehingga kebanyakan nelayan mengolah makanannya dari hasil berkebun seperti jagung, sayur, umbi-umbian serta hasil tani lainnya juga ikan mereka tidak perlu beli, sehingga dapat menghemat pengeluaran. Namun demikian ada 8 orang atau $40 \%$ yang mempunyai pengeluaran antara $R p 1.000 .000,--R p$ 2.000.000,- di mana ada hal-hal yang tidak bisa dihemat seperti biaya pendidikan atau kesehatan. Ada juga nelayan yang mempunyai pengeluaran di atas Rp 2.000.000-, namun hanya 1 orang atau $5 \%$. Hal ini dikarenakan dia harus membiayai pendidikan serta kebutuhan lainnya di perguruan tinggi.

\section{KESIMPULAN}

Ditinjau dari aspek sosial, mayoritas umur nelayan berada di usia produktif, pendidikannya rendah karena mayoritas hanya tamat SD, kesehatannya cukup baik karena mayoritas jarang sakit dan kalau sakit hanya sakit ringan seperti flu. Sedangkan dilihat dari perumahan sudah cukup baik karena lebih dari $50 \%$ sudah mempunyai rumah sendiri yang semi permanen dan permanen.

Ditinjau dari aspek ekonomi, nelayan Desa Bulawan II semuanya memiliki alat tangkap sendiri yang menjadi modal kerja sebagai nelayan. Alat tangkap yang dimiliki ada yang berasal dari pemberian orang tua tetapi kebanyakan dari usaha sendiri untuk membeli alat tangkap. Pendapatan nelayan dirasakan oleh mereka cukup baik karena bagi mereka cukup untuk membiayai seluruh kebutuhan keluarga dengan jumlah tanggungan yang mereka miliki.

\section{DAFTAR PUSTAKA}

Dahuri, R., J. Rais, S.P. Ginting, dan M.J. Sitepu. 2008. Pengelolaan Sumber Daya Wilayah Pesisir dan Lautan Secara Terpadu. PT. Pradnya Paramita: Jakarta.

Faisal, 2003. Metode Jenis penelitian deskriptif. Jakarta

Nasution, M.N. 2005. Manajemen Mutu Terpadu (Total Quality Management). Gahlia Indonesia. Bogor.

Sumarsono, S. 2003. Ekonomi Manajemen Sumber Daya Manusia dan Ketenagakerjaan. Yogyakarta: Graha IImu.

Sugiyono. 2013. Metodelogi Penelitian Kuantitatif, Kualitatif dan R\&D. Bandung: ALFABETA

Simanjuntak, P. 1985. Produktivitas dan Tenaga Kerja Indonesia. Jakarta. 


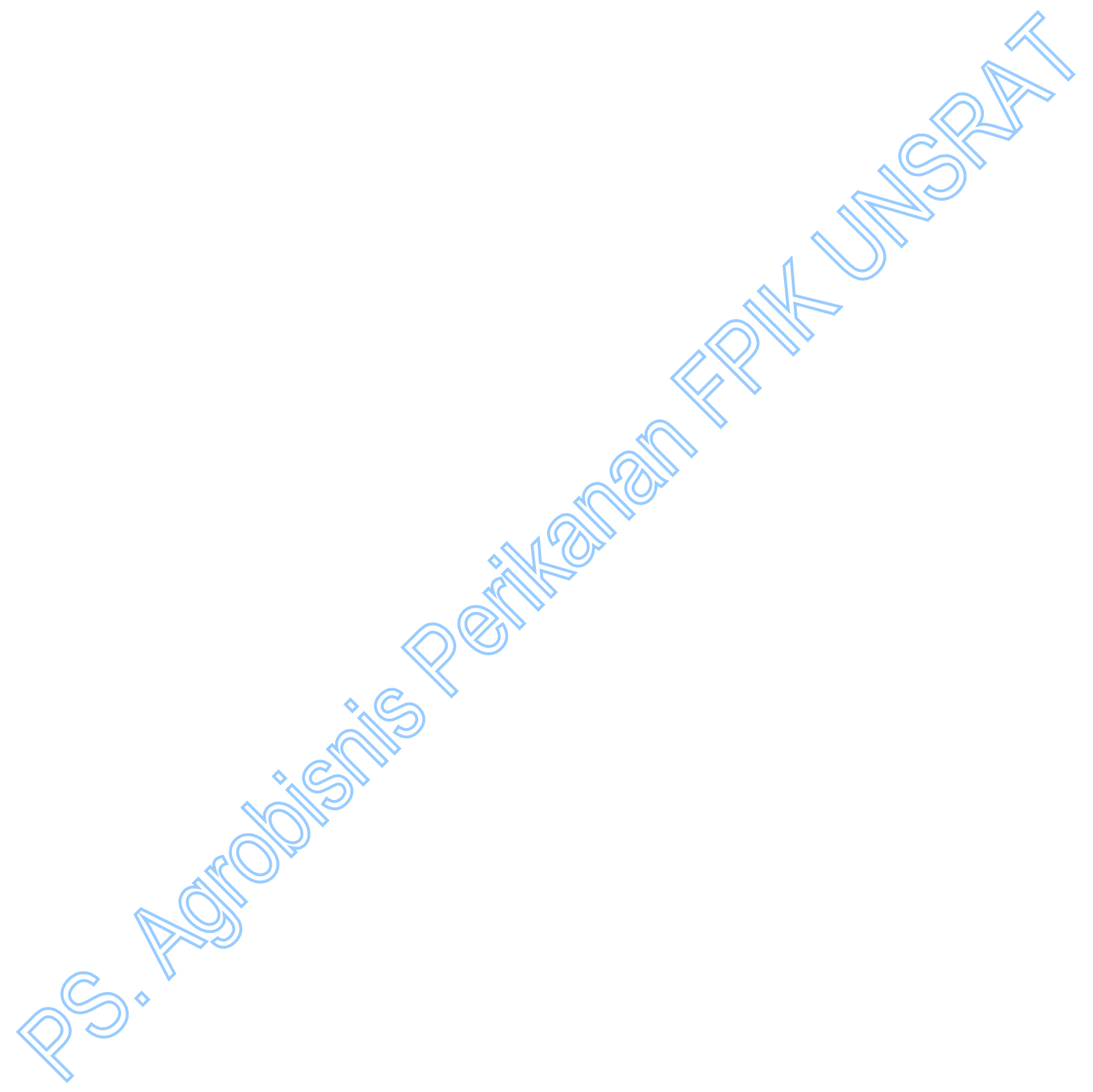

